\title{
CANTORIA \\ DOM E TÉCNICA, A ARTE DA PALAVRA CANTADA
}

Simone Oliveira de Castro

A cantoria é arte que se expressa sobretudo por meio da palavra cantada e improvisada ao som da viola. Seus protagonistas movimentam, pela força de suas vozes, tradição poética que ainda hoje encontra no Nordeste brasileiro seus mais significativos representantes. Rastreando a memória de alguns deles, encontramos na narrativa de cantadores e ouvintes a crença de que ser cantador é um dom e, portanto, essa é categoria importante para a compreensão do universo simbólico que circunda o fazer poético da cantoria de viola. [Abstract on page 246]

CANTORIA, DOM, TÉCNICA, PERFORMANCE.

CASTRO, Simone Oliveira de. Cantoria: dom e técnica, a arte da palavra cantada. Textos escolhidos de cultura e arte populares, Rio de Janeiro, v.7, n.1, p. 179-192, mai. 2010. 


\section{DOM E TÉCNICA}

Eu estou muito agradecido / Por estar neste lugar / Pela minha inspiração / E pela luz do meu olhar / Pelo grande dom que eu tenho / E por ter casa pra morar (Moacir Laurentino, cantador paraibano)

Arte que se traduz no cotidiano de homens e mulheres que desafiam as palavras e dela fazem sua fonte de vida e inspiração, a cantoria trafega no espaço entre o dom e a técnica. Seus criadores consideram-na ao mesmo tempo dom, herança divina dada a poucos escolhidos, e arte que se vale da técnica, do esforço contínuo da mente para aperfeiçoá-la. Algumas vezes, na fala dos cantadores, essas duas noções se confundem de maneira tal, que se chega a supor ser puramente dom aquilo que a técnica lapidada ao longo de uma vida é capaz de produzir em sua beleza poética.

Na narração do poeta Pedro Bandeira, que há mais de cinco décadas dedica-se à cantoria de viola, pode-se perceber o quanto dom e técnica caminham lado a lado:

É... uma parte é dom (...) um dom de Deus. É um dom diferente, né? Uma coisa que acontece no seu cérebro, você tem... como chamam... a veia poética. Ser cantador é um dom (...) eu vou deixar bem claro (...) mas ser cantador especial é um capricho, é um esforço (...) é um esmero (...) uma dedicação. Tem muita gente que podia tá cantando melhor do que o que canta. Por aí você encontra cantador que tem condição de cantar muito melhor, mas tem preguiça de pensar, de raciocinar (...) de mentalizar. Aí isso faz com que ele não encontre o que diga na hora que bate na viola. Então fica claro, cantoria é um dom de Deus, mas ser cantador bom, cantador especial é um esforço mental (entrevista realizada em 11.11.2006 em Juazeiro do Norte, CE).

Bandeira é categórico ao afirmar que ser cantador é um dom. Observa, como todo artista que ama sua criação, que esse dom sem o esforço, sem a técnica, sem o aperfeiçoamento e a dedicação cotidiana pode tornar-se improdutivo. "É um dom diferente", algo especial que toma conta, que "acontece no cérebro", revelando uma poética que só se realiza plenamente pelo esforço contínuo daquele que a possui.

É dom, confirmam muitos cantadores com quem conversei, mas que exige empenho pessoal, que começa no momento em que o cantador se descobre capaz de criar versos de improviso e se estende ao dia de seu último suspiro. Um cantador que deseja crescer em sua arte jamais deixa de se aperfeiçoar, e esse crescimento é sentido e vivido pelo público, que dá o aval para sua longa caminhada. Tornar-se "cantador especial, extraordinário" é trabalho de uma vida inteira. Dos milhares de cantadores espalhados pelo Nordeste e pelo Brasil apenas alguns aparecem e figuram como estrelas no complexo universo da arte de improvisar.

Ao afirmar que "por aí você encontra cantador que tem condição de cantar muito melhor, mas tem preguiça de pensar, de raciocinar (...) de mentalizar", Pedro Bandeira aponta para a necessidade de prática contínua que envolve trabalho mental muito forte. $\mathrm{O}$ dom, sempre valorizado e mencionado pela maioria dos cantadores entrevistados como o principal elemento para se tornar um cantador, só se concretiza, de fato, a partir 
do empenho individual. É no desenvolvimento e no aperfeiçoamento de regras poéticas bem definidas que o poeta alcança a excelência de que fala Bandeira.

O cantador cearense Francisco Maia de Queirós, mais conhecido como Louro Branco, canta desde os 12 anos de idade; sua fala é marcada pelo entusiasmo com que acolhe e acredita no dom, que considera divino:

É, apesar de ser uma profissão que não tem um faturamento alto, mas um dos dons bonito e muito difícil. Simone, não é porque eu sou cantador não, eu não conheço uma arte mais difícil que cantar de improviso. Eu me refiro à cantoria de improviso colocando as pedras no lugar, né? Não tô me referindo a ninguém. Eu canto com todo tipo de cantador, grande e médio, de todo jeito. Agora têm umas cantorias aí que... faltam algumas coisinhas, né? Têm umas paredes que faltam uns tijolos, mas é sempre um dom. Agora, cantoria de improviso bem colocada a pedra no lugar com métrica, rima e oração. (Entrevista realizada em 20.4.2007 em Fortaleza, CE).

Louro Branco muito consciente do dom que possui valoriza sua arte como uma das mais bonitas, elaboradas e difíceis. Mas também, como Pedro Bandeira, vê na arte de improvisar um longo processo, uma espécie de construção em que é preciso ir pondo a cada dia uma pedra, um novo tijolo, formando um alicerce que dê sustentação às paredes que serão erguidas numa longa jornada. O dom, se não garante "alto faturamento", traz para aqueles cantadores que se destacam condições razoáveis de vida e de profissão, como avaliou.

Mesmo não querendo discriminar os colegas, tanto Pedro Bandeira como Louro Branco trouxeram à tona em suas narrações o fato de alguns cantadores, às vezes, não se dedicarem suficientemente ou não possuírem condições favoráveis, internas ou externas, para desenvolver um trabalho com a necessária competência e ser aceitos como grandes repentistas. $\mathrm{O}$ que eles consideram dom, sem a devida habilidade e dedicação, pode tornar-se débil diante de determinadas plateias.

A questão do dom marca de forma constante o discurso dos cantadores sobre sua prática. O cantador João Paraibano é bastante incisivo:

É, certeza pura, porque rimar todo mundo aprende a rimar. Você compra um dicionário de rima, você aprende a rimar [a] qualquer hora que você quiser. Agora, cantar, você não canta sem ter nascido com o dom não, porque você vai rimar, mas você não vai encontrar a oração principal para (...) botar em cada peça que (...) for construir. Você pode fazer o verso, pode rimar, mas não tem poesia você não sendo poeta (Entrevista realizada em 26.4.2007 em Fortaleza, CE).

João não hesita em afirmar que ser cantador é um dom; em sua opinião, essa é a "certeza mais pura" que existe sobre a cantoria e, como os companheiros de profissão, pensa em sua arte como algo engenhoso em que cada peça deve ser construída para que a poesia alcance a beleza poética e técnica, que somente "aqueles que são poetas", que "nasceram com o dom" e o desenvolveram são capazes de oferecer aos amantes do improviso. 
Há todo um conjunto de regras que faz da cantoria uma prática cultural bastante específica. Há uma série de procedimentos poéticos que é aprendida e, principalmente, apreendida, de forma bastante peculiar pelo cantador, e, longe de ser algo sistematizado, explicado e ensinado, essa poética é sedimentada desde cedo, a partir da vivência e da experiência compartilhada com outros poetas.

Para o cantador Sebastião Dias, entretanto, é muito difícil afirmar que ser cantador é um dom; sua narração explicita a dúvida que parece persegui-lo:

Eu creio que seja (...) porque dom é aquilo que tá no seu coração, na sua alma, esse dom para você desenvolver. (...) Agora é muito difícil você explicar o que é assim... a cantoria ser um dom (...) Às vezes fica esse entrave (...) Fica essa dúvida nessa pergunta (...) em todas as respostas que eu dou por isso... O que é dom? Se dom for você fazer uma coisa por amor, que você gosta e que você tem responsabilidade, então cantoria de viola é um dom e divino e sublime, tá certo? (idem).

Sebastião Dias sente dificuldade em se posicionar frente a essa questão. Ora parece assumir que ser cantador é um dom, por considerar que se traz isso no coração, na alma para ser desenvolvido, ora considera que dom é algo divino, sublime e talvez a cantoria não se encaixe nessa dimensão religiosa do sublime, em sua opinião. Por fim, pondera que fazer alguma coisa por amor e com responsabilidade pode ser pensado como um dom, e nesse aspecto sua escolha pela arte do repente assume importância que extrapola esse questionamento, pois a cantoria simboliza a maneira como interpreta e vive seu cotidiano, e, de todas as coisas que já desenvolveu na vida, a cantoria é, sem dúvida, a que lhe dá mais prazer e satisfação: "a cantoria é uma coisa totalmente número um. Cantoria para mim é onipresente, é minha vida e tudo."

Embora relute em admitir com segurança que ser cantador é um dom, Sebastião apresenta a cantoria como algo simbolicamente tão forte em sua vida, que o põe como um observador de seu eu, de seu espírito. "Eu abracei como uma causa, como se fosse meu coração batendo fora de mim a cantoria, certo? Como se fosse minha alma eu [me] vendo nos meus versos."

Ao admitir a possibilidade do dom, Sebastião nele vislumbra uma janela para o desenvolvimento crítico do homem e ao mesmo tempo do artista, este último intrinsecamente relacionado à aceitação ou não do público como parâmetro legitimador do referido dom.

Em meio às narrações e conversas informais com cantadores, e também com ouvintes, a questão do dom aparece, na maioria das vezes, como algo dado, não discutível.

\section{$1 \mathrm{Seu}$ Anacleto Dias fez} 83 anos em 17 de abril de 2008. Não está mais cantando, pois sofreu um AVC que prejudicou seus movimentos e sua fala.
No entanto, também é recorrente a menção à necessidade de aperfeiçoamento, à vontade de querer ser cantador, ao aprendizado, à prática continuada e à observância de cada regra que acompanha os diversos gêneros dessa poética.

Também o cantador Anacleto Dias, no alto dos seus 83 anos, ${ }^{1}$ faz coro com os demais cantadores: 
É um dom. Ser poeta é um dom porque ninguém aprende, sabe? A gente nasce com aquele sentimento e (...) e executa mais ou menos a prática e com a prática a gente desenvolve o modo de cantar. Foi o que aconteceu comigo (...) Foi um dom que Deus me deu, a vontade de cantar e com isso eu me desenvolvi. (entrevista realizada em 14.11.2007 em Assaré, CE)

Como sinalizam os diferentes depoimentos, a prática, no entanto, está intrinsecamente ligada à presença do dom, à vontade de dar continuidade àquele sentimento que o poeta diz possuir dentro de si. Sem ela não há como desenvolvê-lo. E, da mesma forma, sem o dom não há técnica que faça alguém ser um poeta na dimensão atribuída pelos cantadores. A métrica e a rima dessa poesia improvisada podem até ser aprendidas, mas a beleza poética, a intensidade e o alcance da mensagem junto ao público parecem ficar restritos àqueles que possuem o dom. Não podemos, entretanto, esquecer que a presença do dom não indica por si só que ele será desenvolvido por quem o possui. Considero, sob esse aspecto, que muitas pessoas podem ter nascido com o dom para a poesia improvisada e, no entanto, não o quiseram desenvolver.

$\mathrm{O}$ poeta Moacir Laurentino vai além, ao afirmar que existe o que chama de "desnivelamento de dom":

É um dos maiores dons que pode ter. Existe o desnivelamento de dom. Isso eu gosto de dizer. Ninguém pense que todo mundo que inventa de cantar é cantador não (...) E os cantadores (...) que têm o dom de anum preto e de anum branco, de caboré, esses aí não acertam de jeito nenhum (risos) Agora aqueles que são privilegiados pelo alto, por Deus... Deus fez a escolha, tá aqui o dom, o seu caminho é esse aqui. Você vai ser isso aqui. É uma diferença muito grande (...) Tem cantador que fica velho pensando que aprendeu cantar e não sabe cantar de jeito nenhum. Essa é a realidade. Eu não tô aqui apontando ninguém, fulano... não, mas tem. Outros colegas da minha arte sabem disso (...) E ruim é que o cantador ruim não sabe se canta ruim (entrevista realizada em 11.6.2008 em Fortaleza, CE).

Moacir Laurentino é bastante contundente em suas afirmações, a sua fala deixa transparecer, com muita clareza, que nem todos aqueles que se consideram poetas o são, pois esse dom que é dado por Deus também define a "categoria de cada cantador" e alguns serão sempre "caboré ou anum, jamais chegando a galo-de-campina".

É comum entre os cantadores, como entre os demais artistas em outras áreas, o enaltecimento exacerbado de sua arte. Eles costumam situá-la sempre como a mais grandiosa, a mais difícil de ser criada, e, portanto, nela existiriam aqueles considerados os eleitos entre os melhores.

Essa percepção de Moacir pode ser sentida na vivência cotidiana de cantadores e ouvintes. Há toda uma divisão dos poetas em categorias. Aqueles considerados por seus pares e ouvintes possuidores de "dom acentuado" e de nível satisfatório de aperfeiçoamento técnico figuram entre as estrelas da cantoria. São vistos como os maiores cantadores da atualidade, e isso Ihes possibilita agenda constantemente preenchida com compromissos durante o ano inteiro. 
Tudo, porém, se passa entre o dom e a técnica, como corrobora Moacir: "Olhe, (...) ninguém nasce pronto, vai-se aperfeiçoando aos poucos, vai criando coragem de cantar, vai machucando a ideia, vai começando [a] render na cantoria. A prática vai influenciando muito; se ele tiver um dom grande, aí vai em busca do crescimento mesmo" (idem).

2 O cantador Zilmar do Horizonte ao falar apresenta leve gagueira, fato que não se observa quando está cantando.

O repentista Zilmar do Horizonte ${ }^{2}$ chega a afirmar que é mentiroso aquele que não considerar que ser cantador é dom:

Se eu não considerasse eu estava mentindo. O que não considerar que é um dom... é um mentiroso. Um exemplo, a técnica amplia, mas é uma... é talvez a única arte que você só é se tiver nascido (...) Então, só é cantador quem nasceu com o dom. Agora, o dom vem da criação, aí seria saberes sobrenaturais para explicá-la (entrevista realizada em 11.6.2008 em Fortaleza, CE).

Zilmar eleva a questão ao nível do sobrenatural, pois para ele o dom vem da criação, vem de Deus, e, dessa forma, não teria como explicá-lo. Por outro lado, é necessária técnica para ampliar esse dom "herdado de forma divina".

Aqui percebemos mais uma vez a supervalorização da cantoria. Se pensarmos, pois, na arte e em suas diferentes formas de expressão é provável que outros artistas considerem, da mesma forma que Zilmar e muitos cantadores, que sua arte é a única necessitada de dom para expressá-la.

No entanto, o percurso da cantoria vai insinuando, a cada depoimento dado, que o dom e a técnica caminham de mãos dadas nessa arte complexa que faz de homens e mulheres, na maioria sertanejos, grandes privilegiados. Homens e mulheres que, muitas vezes com pouca escolaridade, alguns ainda hoje apenas alfabetizados e outros com nível superior, transformam palavras cotidianas em versos, então admirados, desejados e buscados por seus ouvintes, que encontram nessas palavras significados que traduzem sentimentos ora compartilhados, ora desconhecidos.

Já o poeta Geraldo Amâncio, ao se referir à arte de ser cantador como sendo um dom, desafia: “(...) até que alguém me prove o contrário, eu não conheço nenhum repentista sem ter o dom da poesia. Eu nunca ouvir falar assim: fulano aprendeu a cantar através de escola. Não, eu acho ou tem o dom ou não canta" (entrevista realizada em 8.2.2006 em Fortaleza, CE).

Geraldo defende que ser cantador é um dom e duvida que alguém que não possua o "dom da poesia" seja capaz de fazer o que ele, ao longo dos seus mais de 40 anos de profissão, e alguns outros cantadores têm feito: viver da palavra improvisada, cantada e metrificada, cotidianamente. Além disso, o poeta sente-se privilegiado, pois acredita que a cantoria seja também uma espécie de "milagre", "uma bênção deixada por Deus" para uns poucos que conseguem com dedicação e persistência levar à frente uma arte "poética tão perfeita". "A maior de todas!"

Eu ainda considero a maior arte do mundo. Fala-se muito em oralidade, eu acho um milagre um cantador viver quatro décadas ou meio século da orali- 
dade sem repetir. Então, é o maior milagre que eu conheço em termo de arte. É, na minha óptica, a cantoria a maior bênção que Deus deixou em termo de arte, de tudo (idem).

Geraldo Amâncio faz parte de um "restrito grupo" de cantadores que conseguiu fazer de seu "dom" uma arte aceita e respeitada. A primazia, o empenho e a virtuosidade na execução, elaboração e no aprimoramento dessa poética deram a esse grupo a oportunidade de viver exclusivamente de sua arte. Daí porque a valorização do que chamou de "viver da oralidade sem repetir".

Há que considerar sob esse aspecto que a configuração desse restrito grupo se inscreve numa espécie de disputa política no campo da cantoria; na conquista de um espaço privilegiado que permeia o desejo de todo cantador e que motiva, de certa maneira, as transformações dessa arte.

Disputa que vai muito além da questão do dom, pois indica aprendizado, maneiras de lidar e transitar em espaços diferenciados, vivências com pessoas e situações-chave que abrem caminhos no campo cultural.

Em sua fala a cantoria alcança a dimensão de dom porque é uma "bênção de Deus, um milagre" que possibilita a pessoas como ele se comunicar e viver de palavras que, embora as mesmas, são sempre outras e trazem uma mensagem nova, não repetida para seus ouvintes. Paradoxo da poesia oral que sendo matriz se reproduz continuamente de formas diversas na voz desses poetas.

Sebastião da Silva, cantador paraibano, apoiando as palavras de Geraldo, da mesma forma não tem dúvida de que ser cantador é um dom e explica que, às vezes, pode até haver alguém que cante sem ter o dom, mas não possui certamente a mesma maestria:

Ah! Sem dúvida! Sem dúvida! Eu acredito que exista muita gente que cante até sem o dom de cantar, sem o dom de ser cantador, certo? Muita gente (...) que canta porque ouviu alguém cantar, aprendeu, arranjou... emendou uma frase de um com outro sabe... feijão... todo mundo sabe que feijão rima com sabão, que (...) calção rima com... com timão, entendeu? E que (...) saudade rima com cidade, mas a questão não é rimar, não é só rimar, é a montagem do verso. É a beleza do conjunto da obra. O bom ritmo, a boa voz, a boa oralidade, a boa métrica. E também um pouco da arte cênica que é necessário que a cantoria não seja aquela coisa do cantador cantar só olhando pros pés. Ele tem (...) que levantar, que jogar, que (...) dominar (...) com o olhar, com a expressão, com a palavra, com a mensagem (entrevista realizada em 30.6.2007 em Fortaleza, CE).

Sebastião defende a cantoria como dom por acreditar que a arte de improvisar não se restringe à questão da rima ou da técnica propriamente dita. Supõe que qualquer pessoa possa cantar decorado, rimando uma palavra com outra, aprendendo alguns versos, mas a cantoria é bem mais do que isso. Ela expressa uma "mensagem que se completa na beleza que compõe o conjunto da obra" poética. Essa seria a principal diferença apontada por Sebastião entre aqueles que possuem o dom - e conseguem dar vida a 
todo um "arcabouço técnico" que envolve a tradição da cantoria, destacando-se por isso, e os que se aventuram nesse campo, partindo apenas da técnica, do arranjo de uma palavra com outra.

Sebastião vê a arte do improviso como uma espécie de jogo que se estabelece entre o público e o cantador, e que envolve, sobretudo, o domínio pessoal deste último o que em sua opinião caracterizaria o dom de se comunicar não apenas usando palavras repetidas e decoradas, mas criando uma mensagem que alcança o outro intensamente no momento da performance.

Sebastião parece ter captado a essência de sua arte, poética da palavra e do corpo; a cantoria se insinua em sua narração como "mensagem" que envolve elementos espirituais, já que se configura como dom, e elementos corporais, gestuais e técnicos que emergem na performance do cantador.

A performance, nesse sentido, é essencial, acredita Sebastião, para o bom andamento da cantoria. É preciso ter o domínio do corpo, da mente e da poesia para que a comunicação com o público se realize de forma plena por meio da mensagem, da palavra cantada do poeta. Isso porque a “(...) performance implica competência. Além de um saber fazer e de um saber dizer, a performance manifesta um saber ser no tempo e no espaço" (ZUMTHOR, 1997:157).

A partir das narrações vamos apreendendo os diferentes sentidos que cercam essa arte; apontada sempre como um dom, ela em momento algum prescinde de técnica elaborada que, passando pela palavra, alcance também o corpo em sua performance encantatória. No entanto, essa técnica passa, muitas vezes, despercebida nos discursos e nas práticas de cantadores e ouvintes porque está incorporada no fazer cotidiano da cantoria.

O cantador Zé Viola, no entanto, amplia a discussão avaliando que além do dom de fazer repente é necessário o dom da paciência:

Ser cantador é um dom. Precisa do dom de fazer repente, né? E do dom de ser cantador e de... de transmitir com a força da alma, de ter aquele dom de... de receber a plateia como ela é. Precisa desse dom, de ter paciência com quem tira a paciência, que isso é difícil, Simone: ter paciência com quem tira a paciência da gente. $\mathrm{E}$ isso existe de vez em quando, constantemente. É (entrevista realizada em 3.3.2007 em Limoeiro do Norte, CE).

Zé Viola em sua narração traz uma análise interessante para compreendermos que para além da posse do "dom de transmitir a poesia com a força da alma", também "o dom da paciência" é requisito fundamental para complementar o dom de fazer repente, e o cantador deve exercitá-lo com frequência.

Provavelmente Zé Viola refere-se à habilidade de que o cantador necessita para desenvolver um bom trabalho junto ao público, pois, além de ser um "repentista nato", a forma como ele consegue lidar com qualquer tipo de ouvinte é também essencial para o andamento de sua carreira artística. Sugere, nesse sentido, que ser cantador exige generosidade e paciência que devem ir além da vaidade de ser poeta. 
Ao cantar para público diversificado e em diferentes ambientes, que variam do teatro nos grandes centros urbanos ao bar nas periferias das cidades, o cantador vive muitas situações de "tirar a paciência", como sugeriu Zé Viola, mas é exatamente sua capacidade de lidar com a plateia que engrandece seu verdadeiro dom, o de improvisar sempre, na vida e na arte.

Arte que, imbricada entre o dom e a técnica, deixa entrever, nos diferentes discursos, a importância atribuída por cantadores e ouvintes a essa dimensão simbólica na qual está inserida a cantoria e que faz valorizar o poeta por trás da palavra cantada, improvisada e que o diferencia como detentor de um discurso que é ao mesmo tempo matriz e desdobramento de diversos sentimentos do público e dele próprio. Essa condição o faz aparecer como detentor de saber especial e único, de dom desejável e admirado pela dimensão social que o cantador alcança junto à coletividade que representa e pela qual se sente representado.

\section{AH, SE EU TIVESSE ESSE DOM!}

Elemento essencial da cantoria, o público também manifesta a certeza de que ser cantador é um dom "sagrado e divino". Em geral, o público tem orgulho dos poetas e considera grandioso seu dom, percebendo-os como pessoas privilegiadas. O ouvinte Cauby Holanda, por exemplo, é enfático em sua afirmação:

É dom, não existe como... Olha, se não for dom, não adianta se meter, não adianta querer fazer castelo de areia porque vai passar vergonha, não adianta. Você vê eu; pra mim fazer uma estrofe nem na escrita num vai porque eu não tenho o dom de fazer poesia na hora. Você vê esses homens, eles constroem umas estrofes mais mirabolantes do mundo (...) Mas não adianta dizer (...) como se faz porque é um dom sagrado e divino (...) Já nasce com o dom; se não for, não adianta se meter não que (...), se não tiver dom, se for pequeno, se for pra cantar com os que tão aí hoje, é besteira. Não adianta não que é mesmo que enfrentar um foguete carregado de ogiva viu? (...) Os homens são uns titãs, não adianta não (risos) (entrevista realizada em 16.12.2006 em Fortaleza, CE).

Como todo amante da cantoria, Cauby reconhece a grandeza dessa arte; seu posto de divina, de dom é incontestável em sua fala. Em seu entusiasmo hiperbólico, eleva os cantadores à categoria de titãs, como os da mitologia, pois só quem possui "dom sagrado e divino", como o de ser cantador, é capaz de criar uma poesia tão rica e elaborada de repente, no improviso.

Tentar adentrar esse universo sem ter o dom é "perda de tempo, é besteira", é construir "castelo de areia". Exigente, o ouvinte atento distingue o "titã do mortal" no combate por meio da palavra cantada, ritmada, metrificada e, acima de tudo, coerente em sua poética e na mensagem plena de significados que traduz para aqueles que com ela se identificam. Cada estrofe é aplaudida de acordo com a dimensão que alcança pela maestria do poeta. 
Percebemos que os ouvintes são muito mais enfáticos do que os próprios repentistas na afirmação do dom. Em seus depoimentos mostram-se entusiasmados, genuínos defensores do dom dos poetas que admiram. Também ficam claras as várias categorias em que os cantadores podem estar inseridos, mas parece que apenas os "titãs" são considerados, pelos ouvintes, herdeiros do "dom de ser poeta".

Muitos ouvintes admiram tanto esse dom, que guardam dentro de si o desejo de também ser cantador, mas, porque consideram que já se nasce poeta, conformam-se em ser amantes da poesia. Célio Uchôa traz em sua fala bom exemplo:

O cantador nasce poeta e normalmente (...) nasce no sertão. Ele vem... ele já traz na veia a poesia (...) o poeta ele não se faz, o poeta nasce feito. Ele vai aprimorando-se (...) Ser um cantador é uma dádiva de Deus. Ser um cantador é preciso que ele nasça já com aquela sorte. Ser cantador pra mim, dentro da nossa cultura, é máximo. Na nossa cultura popular é o máximo o cantador (...) É e um dom de Deus, uma coisa especialíssima. Ah, se eu fosse um cantador! (entrevista realizada em 7.3.2007 em Fortaleza, CE).

"Ah, se eu fosse um cantador!" Assim Célio Uchôa deixa vir à tona seu encantamento pela cantoria, por esse dom que considera "o máximo" dentro do que se convencionou chamar de cultura popular. Essa "dádiva" com que Deus presenteia alguns poucos é vista por grande parte dos ouvintes como algo muito especial. É uma sorte, uma estrela que acompanha o escolhido do momento em que ele nasce até seu desencantamento.

Zumthor (1993, p. 67), reportando-se aos intérpretes medievais da poesia oral, lembra que "pela boca, pela garganta de todos esses homens (muito mais raro, sem dúvida, pela dessas mulheres) pronunciava-se uma palavra necessária à manutenção do laço social, sustentando e nutrindo o imaginário, divulgando e confirmando os mitos, revestida nisso de uma autoridade particular"

O fascínio que anima o ouvinte de cantoria é perceber que o cantador traduz em linguagem poética o que ele próprio não consegue expressar. O ouvinte projeta-se no poeta, considerando que ele é uma espécie de porta-voz de seus sentimentos. O "dom dado por Deus" e desenvolvido com maestria no contexto cultural no qual está inserido autoriza o cantador diante de seu público e faz com que se torne um artista reconhecido em meio ao diversificado ambiente social do cotidiano dos ouvintes.

E o cantador continua sendo figura de destaque para seus ouvintes: "ele é o máximo!" Hoje, tem circulado em espaços bem diferenciados daqueles comuns no sertão, onde Célio vivenciou as primeiras cantorias e se emocionou com a riqueza de versos e estrofes, que traziam notícias das diferentes veredas por onde peregrinavam os poetas.

O ouvinte, que também migrou para outros espaços, continua reverenciando o cantador como rei da palavra, pois consegue transformar seus sentimentos e os alheios em poesia pura, como revela grande parte dos depoimentos.

Independente de parentesco, ser cantador aparece em muitos relatos dos ouvintes não como algo hereditário, como considerou Zé de Aurélio, outro amante da poesia improvisada: 
Cantoria é um dom porque tem tantos que peleja pra ser poeta e não é (...) Ele nasce com aquele dom. E tantos cantador que vêm aí que nem o pai foi cantador, nem avô, como essa jovem guarda que tem aí (...) Que não foi cantador o avô, nem pai, nem nada, nem mãe e ele se torna um cantador. Eu digo que é um gênio, é um dom que vem nele, né? (...) Eu acredito que aquilo é um dote mesmo que Deus deu a ele, né? Você... na hora que nasce Deus the dá seu dote. Eu penso que é assim. Deus lhe dá pra você seguir aquele caminho. É o que Deus Ihe deu você vai seguir. Eu acredito que é um dote e muito bem dado porque eu primeiramente eu digo, se eu fosse um cantador daqueles não muito pequeno eu agradecia muito a Deus (entrevista realizada em 4.3.2007 em Limoeiro do Norte, CE).

Como Célio Uchôa, Zé de Aurélio gostaria de ter sido um cantador "daqueles não muito pequeno". Mas esse foi "dote" que ele não obteve na vida, não recebeu de Deus. A genialidade de um poeta repentista é considerada algo "natural", uma herança divina e não terrena, como supõe Zé de Aurélio. É uma caminhada que já vem traçada por Deus, pois aqueles que se aventuram, "pelejam", mas não nasceram poetas dificilmente ou jamais obtêm êxito. Um dom que pode premiar mais de uma pessoa por família, já que temos histórias de cantadores que são filhos de cantadores, mas também, vemos muitos poetas em cuja família ninguém possuía ou possui tal dom e são grandes repentistas.

Parece haver um imaginário que perpassa a vida de ouvintes e cantadores quando se referem ao dom de ser poeta; há, aliás, redundância nos depoimentos, como se o discurso fosse sempre o mesmo, incorporado ao longo das gerações de ouvintes, mudando apenas o personagem que o reproduz.

Orlando Queiroz, apologista apaixonado da cantoria, é cauteloso ao falar sobre o dom de ser cantador:

Olhe, os próprios cantadores, se você perguntar pra eles, eles vão te dizer o seguinte: o cantador, o repentista é um dom de Deus, já nasceu com aquele dom. E, eu até me questiono, será que a pessoa nasceu com aquele dom? (...) se você perguntar se Ivanildo quando menino queria ser cantador, eu acho que não. Ele foi praticamente obrigado a ser cantador pelo seu pai, também repentista, José Faustino Vila Nova, que era um extraordinário cantador da época, década de 1950, 1940, e que praticamente, obrigou Ivanildo a acompanhá-lo (...) Tem o dom? Deve ter. Mas será que só pelo dom, ele seria hoje o cantador do século? Eu acredito que não. Então, primeiro, tem o dom, tudo bem, vamos concordar. Tem que ter o dom pra ser cantador. Depois, tem que ter uma força de vontade muito grande porque, realmente, não é uma arte muito simples. As pessoas que conhecem cantoria sabem a dificuldade que é fazer o improviso. (...) Então, é muito difícil. Precisa então, ter força de vontade (entrevista realizada em 14.1.2002 em Fortaleza, CE).

Embora reticente quanto a afirmar o dom de ser cantador, Orlando acaba por render-se ao que praticamente todos os cantadores afirmam. Mais uma vez a possibilidade do dom é permeada por "força de vontade", empenho, esforço individual que pode levar um poeta a se destacar. 
Orlando, como os demais entrevistados, tanto cantadores como ouvintes, destaca sempre esta máxima: de que o dom por si só não garante êxito, é preciso comprometimento, pertinácia, grande esmero pessoal para tornar-se um "cantador excepcional" e figurar nos quadros da memória das gerações de ouvintes que se sucedem na apologia dessa arte.

Reforça ainda que a cantoria representa poética muito complexa e de difícil condução se não for encarada com extrema seriedade. Talvez por isso pensar na cantoria como dom que se vale da técnica continuada, do esforço e aprimoramento do cantador seja um caminho possível para refletir sobre essa arte, uma vez que, reiterando, a questão do dom é a mais recorrente no discurso de cantadores e ouvintes.

O próprio Ivanildo Vila Nova, falando das novas gerações de cantadores, afirma que "os cantadores de hoje são os que vêm mais por influência da cantoria. Então, pela evidência da cantoria hoje vêm surgindo novos cantadores, tá certo? Porque já nasceram com o dom e porque estão vendo a cantoria em evidência" (entrevista realizada em 19.12.2001 em Fortaleza, CE).

A fala desses poetas e admiradores põe a cantoria exatamente entre o dom e a técnica. Um "saber especial" vivenciado, aprendido e apreendido no cotidiano da cantoria. Poética que imbrica a todo o momento arte e vida para dar vazão a sentimentos que se transformam em palavras metrificadas, rimadas, cantadas.

Até hoje não se tem notícia de escolas ou cursos que ensinem alguém a dominar a arte do improviso, como a dominam os cantadores nordestinos, obedecendo a regras que dizem respeito a cada gênero no qual se pode improvisar.

As lembranças que trago de minha convivência com esses poetas e seus ouvintes e do amor com que os vejo conversando sobre cantoria, e não estou falando somente de minhas entrevistas, levam-me a refletir a respeito de que, de fato, deve existir algo a mais nessa arte, que não é só trabalho, não é só técnica, não é só a garantia da sobrevivência nem é só vaidade, da qual nenhum humano está isento.

Embora pelos relatos seja muito difícil afirmar o que seja um dom, para a maioria dos cantadores e ouvintes é aceitável que essa arte seja algo divino, sublime e abençoado por Deus. Uns e outros entendem que ser cantador é ganhar um prêmio, é ser herdeiro de um saber que alguns poucos recebem e é preciso levar adiante.

Quando esses homens tocam o pinho e abrem seus corações e mentes para iluminar milhares de palavras que ditas de outra maneira seriam apenas repetições, eles estão movimentando sentimentos, sensações, lembranças e memórias que são compartiIhadas por eles e seus ouvintes.

Há na poesia cantada e improvisada da cantoria uma mensagem que, para além do significado das palavras, ressoa como um momento vivido, mas também como algo novo, nunca ouvido, sentido ou experimentado, e que pertence a todos aqueles que escutam e fazem ecoar as vozes ali representadas. Porque a poesia busca expressar exata- 
mente o além do cotidiano, a beleza ainda não vista, a sensação ainda não sentida e que se concretiza por intermédio do cantador em presença de seu público.

Esta poesia oral improvisada e cantada, a arte da cantoria, e suas motivações formam o fio condutor de meu olhar de pesquisadora. Quando recordo Alberto Porfírio dizendo que a cantoria foi e continua sendo a alavanca que impulsiona sua existência; Pedro Bandeira com lágrimas nos olhos lembrando-se de seu avô cantador; Moacir Laurentino recitando um improviso que ouviu de Pinto do Monteiro; Geraldo Amâncio falando da grandiosidade dos irmãos Batista; Cauby Holanda, Célio Uchôa, Zé de Aurélio, Orlando Queiroz, Zé Maria Guerreiro, dona Socorro e tantos outros ouvintes emocionados declamando estrofes completas de cantorias que marcaram para sempre suas vidas, vejo nisso tudo um dom, um grande dom.

Talvez o maior dom que a cantoria represente seja de expressar com beleza poética os sentimentos vividos e os não vividos, os sonhos reais e outros jamais imaginados, as certezas e incertezas da vida de quem tem consciência de que está neste mundo de passagem e de que necessita de um pouco de poesia para levar à frente essa caminhada terrena.

É por meio desse "dom" que esses poetas se tornam imortais, perpetuam-se em outras vozes, em outros corpos. Provavelmente por isso a cantoria assume para cantadores e ouvintes valor tão intenso, e seu alcance é pleno e duradouro porque não se faz na quantidade, mas na qualidade da emoção que desperta.

Emoção às vezes contida num calmo sorriso, às vezes extravasada na gargalhada, no aplauso entusiasmado, no grito, no mote sugerido, no gênero pedido, como pude perceber nas cantorias e festivais que venho acompanhando nos últimos oito anos. Emoção carregada de cotidianidades, em que talvez esteja sua profundidade.

Entre o dom e a técnica fica a certeza de uma arte feita por homens e mulheres de carne e osso, mas que ousam recriar o dia a dia, dando-lhe o sabor especial da poesia ou que, muitas vezes, se deixam levar pelo inusitado, trazendo para esse cotidiano a possibilidade de vivenciar o sublime e o desconhecido. Isso, porém, não os exime de suas disputas por conquistar espaços, de suas vaidades, de seus defeitos, das lutas constantes para permanecer por mais tempo no "plantel" de sua arte.

Arte feita também por seus amantes, homens e mulheres que se realizam através dessa poesia. Que amam e odeiam com igual intensidade os poetas e seus rivais, que exaltam e desprezam com o fervor de um torcedor apaixonado que elege, como sendo seu o "time de estrelas", os que irão brilhar no mundo da cantoria.

\section{REFERÊNCIAS BIBLIOGRÁFICAS}

BENJAMIN, Walter. Magia e técnica, arte e política. São Paulo: Brasiliense, 1994.

BOURDIEU, Pierre. O poder simbólico. Rio de Janeiro: Bertrand Brasil, 2003.

CASCUDO, Luís da Câmara. Vaqueiros e cantadores: folclore poético do sertão de Pernambuco, Paraíba, Rio Grande do Norte e Ceará. Rio de Janeiro: Ediouro, s/d. . Dicionário do folclore brasileiro. São Paulo: Global, 2000. 
MOTA, Leonardo. Cantadores: poesia e linguagem do sertão cearense. Rio de Janeiro/Brasília: Cátedra/INL, 1976. . Violeiros do Norte: poesia e linguagem do sertão nordestino. Rio de Janeiro/Brasília: Cátedra/INL, 1976. . Sertão alegre: poesia e linguagem do sertão nordestino. Rio de Janeiro/Brasília: Cátedra/INL, 1976.

RAMALHO, Elba Braga. Cantoria nordestina: música e palavra. São Paulo: Terceira Margem, 2000.

SANTOS, Idelette Muzart Fonseca dos. Memória das vozes: cantoria, romanceiro \& cordel. Salvador: Secretaria da Cultura e Turismo, Fundação Cultural do Estado da Bahia, 2006.

ZUMTHOR, Paul. A letra e a voz: a "literatura medieval". São Paulo: Companhia das Letras, 1993. . Introdução à poesia oral. São Paulo: Hucitec, 1997. . Tradição e esquecimento. São Paulo: Hucitec, 1997.

Simone Oliveira de Castro é mestre em história social pela PUC-SP, doutora em sociologia pela UFC e professora do Instituto Federal de Educação, Ciência e Tecnologia do Ceará. 